\title{
O Uso de Fotografias para (Re) Contar a História na Educação Infantil
}

\author{
El Uso de Fotografías para (Re) Contar la Historia en la Educación \\ Infantil \\ The Use of Photographs to (Re) Tell History in Early Childhood Education
}

Dynara Martinez Silveira ${ }^{1}$

\begin{abstract}
Resumo
Esta pesquisa desenvolvida junto aos alunos do Pré-Escolar tem como objetivo identificar as relações estabelecidas pelas crianças acerca de seu tempo e espaço escolar, a partir da análise de fotografias antigas e recentes, a fim de possibilitar uma compreensão sistemática e crítica da realidade. Nesta, será possível perceber a luta que a Educação Infantil vem travando para imprimir, junto aos pequenos, uma educação de qualidade, aliada ao cuidado. Mais do que isso, trata do ensino de História na Educação Infantil utilizando mídias imagéticas como fotografias que tencionaram levá-los à análise crítica da realidade, de diferentes espaços e tempos na (re)construção de seus conhecimentos. É através do uso de imagens fotográficas que tentamos conduzir as crianças do Pré-Escolar a estabelecer relações históricas de tempo e espaço entre seu grupo social e outros grupos que por ali passaram, procurando recontar, de forma clara e concreta, a história da Escola Municipal de Ensino Fundamental Marechal Castelo Branco. Pensamos, assim, ser possível, que as crianças pequenas formulem noções e percepções acerca da história através da análise e discussão de fotografias antigas.
\end{abstract}

Palavras-Chave: Educação Infantil; História; fotografias; mídias.

\section{Resumen}

Esta investigación desarrollada junto a los alumnos del Pre-Escolar tiene como objetivo identificar las relaciones establecidas por los niños acerca de su tiempo y espacio escolar, a partir del análisis de fotografías antiguas y recientes, a fin de posibilitar una comprensión sistemática y crítica de la realidad. En esta, será posible percibir la lucha que la Educación Infantil viene trabando para imprimir, junto a los pequeños, una educación de calidad, aliada al cuidado. Más que eso, trata de la enseñanza de Historia en la Educación Infantil utilizando medios imaginarios como fotografías que han pretendido llevarlos al análisis crítico de la realidad, de diferentes espacios y tiempos en la (re) construcción de sus conocimientos. Es a través del uso de imágenes fotográficas que intentamos conducir a los niños del Pre-Escolar a establecer relaciones históricas de tiempo y espacio entre su grupo social y otros grupos que por allí pasaron, buscando recontar, de forma clara y concreta, la historia de la Escuela Municipal de Enseñanza Fundamental Mariscal Castelo Branco. Pensamos, así, ser posible, que los niños pequeños formulen nociones y percepciones acerca de la historia a través del análisis y discusión de fotografías antiguas.

Palabras claves: Educación Infantil; historia; fotografías; medios de comunicación.

\begin{abstract}
This research developed with students of the Pre-School aims to identify the relationships established by children about their time and school space, based on the analysis of old and recent photographs, in order to enable a systematic and critical understanding of reality. In this, it will be possible to perceive the struggle that the Child Education has been blocking to print, together with the small ones, a quality education, allied to the care. More than that, it deals with the teaching of History in Early Childhood Education using imagery media as photographs that intend to take them to the critical analysis of reality, of different spaces and times in the (re) construction of their knowledge. It is through the use of photographic images that we try to lead the children of
\end{abstract}

\footnotetext{
${ }^{1}$ Mestra em Educação; Universidade Federal de Pelotas - UFPEL; Jaguarão, Rio Grande do Sul, Brasil; dynara.silveira@gmail.com
} 
the Pre-School to establish historical relations of time and space between their social group and other groups who have gone through it, trying to recount in a clear and concrete way the history of the Municipal School of Fundamental Education Marechal Castelo Branco. We thus think that it is possible for young children to formulate notions and perceptions about history through the analysis and discussion of old photographs.

Keywords: Early Childhood Education - History - photos - media.

\section{Introdução}

É através do uso de imagens fotográficas que tentamos conduzir as crianças do PréEscolar a estabelecer relações históricas de tempo e espaço entre seu grupo social e outros grupos que por ali passaram, procurando recontar, de forma clara e concreta, a história da Escola Municipal de Ensino Fundamental Marechal Castelo Branco. Pensamos, assim, ser possível, que as crianças pequenas formulem noções e percepções acerca da história através da análise e discussão de fotografias antigas. Objetivamos com este trabalho estimular as crianças no processo de estabelecimento de relações entre o tempo e o espaço escolar, a partir da análise de fotografias antigas e recentes. Nestas fotografias, os alunos aparecem como protagonistas. Desta forma, acreditamos ter possibilitado uma compreensão sistemática e crítica da realidade.

No transcorrer deste texto, situaremos o leitor acerca da importância do trabalho institucionalizado com crianças menores de 06 anos, através de projetos que estimulem a construção de conhecimentos e visem à qualidade na Educação Infantil que, por muito tempo, esteve atrelada apenas ao cuidado do corpo. Para dar início a esta caminhada, foi necessário que nos debruçássemos sobre algumas perspectivas teóricas, tendo por base a legislação educacional vigente e o ponto de vista de autores como: Kuhlmann Jr. (2003), Mauad (1996), Rego (1995) entre outros. Estes vêm de encontro a aspirações pessoais, afinal educar não pode ser um trabalho unilateral, não pode ser transmitido do professor para o aluno, devendo ser construído entre todos os envolvidos neste processo de desenvolvimento social, pessoal e psicológico.

Toda caminhada leva a algum lugar. No nosso caso, trilhamos este caminho em busca de conhecimentos. Desta forma, traremos a narrativa destes passos que deram vida ao projeto proposto aos alunos do pré-escolar, utilizando fotografias como recurso, entre outras mídias, e é através de imagens que será possível perceber a participação das crianças. Por fim, ou melhor, por momento, serão trazidas algumas breves conclusões acerca do trabalho desenvolvido.

\section{Situando o Leitor}


Acreditando que a educação deve ser um processo de ensino-aprendizagem e que este processo não pode ser desconsiderado pela pouca idade das crianças que frequentam as turmas de Educação Infantil, neste caso, o Pré-Escolar (05 anos), nada mais eloquente do que desenvolver debates que gerem condições para que a própria criança se torne parte ativa na investigação de um tema. Desta forma, procurou-se instigar estas crianças a observar, relatar acontecimentos cotidianos, questionar e formular hipóteses, conhecer o contexto; estes ainda foram levados a localizar-se no tempo e espaço, com isso houve uma troca de informações que resultaram na construção ou mesmo reconstrução de conhecimentos acerca deste assunto.

Geralmente, o ensino da História, nas escolas, acontece de forma estática, principalmente, através de livros didáticos, sem movimento e sem questionamentos. Acaba-se por esquecer que estas crianças, antes mesmo de entrarem na escola, já são parte ativa no grupo social em que estão inseridos, concordamos, assim, com a seguinte afirmação:

[...] a criança, ao chegar à escola, já sabe ler histórias complexas, como uma telenovela, com mais de trinta personagens e cenários diferentes. Essas habilidades são praticamente ignoradas pela escola, que, no máximo, utiliza a imagem e a música como suporte para facilitar a compreensão da linguagem falada e escrita, mas não pelo seu intrínseco valor (MORAN, 2008, p. 5)

Levando em consideração que esta fase da infância é de efervescência em relação à aquisição e elaboração de novos conhecimentos, cabe ao professor desenvolver nestas turmas projetos interessantes com objetivos e funções adequadas ao desenvolvimento social, cultural e psicológico dos alunos. Desta forma, foi eloquente propor aos pequenos conhecer a trajetória histórica da Escola Mal. Castelo Branco através de fotografias antigas. Mas, para que a aprendizagem não acontecesse de forma estática, os alunos foram inseridos nesta história através da representação, do reviver as imagens que analisaram nas fotografias.

Esperamos, assim, ter contribuído para que os alunos construíssem noções de espaço e tempo, inserindo-se na História da nossa Escola, de forma individual e em grupo para, assim, conhecer alguns aspectos do passado e sentirem-se atores na construção do presente. Não é novidade a afirmação de que a Educação Infantil não só no Brasil, mas no mundo está em constante expansão. Atrelada a esta surgem melhorias, problemas, lutas e discussões em que está centralizado o atendimento às crianças menores de seis anos, indiferente da classe social a que pertençam. Com base em Kramer (1988), é possível dizer que só em meados dos anos 70, o trabalho com crianças menores de 06 anos concebeu-se em caráter histórico, isso em razão da expansão do movimento social. Segundo Kuhlmann Jr. (2003, p.469),

[...] pode-se falar em "educação infantil" em um sentido bastante amplo, envolvendo toda e qualquer forma de educação da criança na família, na comunidade, na sociedade e na cultura em que viva. Mas há outro significado, mais preciso e 
limitado, consagrado na Constituição de 1988, que se refere à modalidade específica das instituições educacionais para a criança pequena, de 0 a 6 anos de idade.

A Constituição Federal de 1988 representa a primeira conquista da Educação Infantil no campo social e político e garante, em sua redação, que ela seja dever do Estado, a ser implementada em creche e pré-escola, às crianças zero a seis anos de idade. No entanto, a creche continuou sendo vista como um favor, ligada ainda ao Bem-Estar e a Saúde, enquanto a pré-escola era ligada à Educação. Sendo que ambas, efetivamente, após articulações de diferentes setores da sociedade, passaram a compor de forma significativa o campo educacional, em 1996, com a Lei de Diretrizes e Bases da Educação 9394/96, a Educação Infantil foi incorporada à Educação Básica, rompendo com a ideia desses espaços como segregadores sociais.

Outras iniciativas e concepções continuaram a se desenvolver e deram forma, em 1998, ao Referencial Curricular Nacional para a Educação Infantil e as Diretrizes Nacionais para a Educação Infantil, ambos os documentos formulados pelo Ministério da Educação e Cultura - MEC e, teoricamente, para todas as crianças, independentemente se na cidade ou campo. Na virada do século XX para o XXI, a LDB trouxe a garantia de uma Educação Infantil de qualidade. Entretanto, ainda se espera a efetivação de qualidade real, com valorização de crianças e educadores e um alcance maior, ou seja, não só para as populações urbanas, mas também para as do campo. Para CAMPOS (2010, p. 09):

[...] essa formulação trouxe várias mudanças significativas na organização da oferta de atendimento em creches e pré-escolas: a educação infantil faz parte do direito à educação desde o nascimento, embora não com o caráter de obrigatoriedade para as famílias; as creches, agora definidas de acordo com a faixa etária atendida (crianças entre 0 e 3 anos de idade), foram incluídas no setor educacional, transferidas de áreas como a assistência social e a saúde.

Cabe ressaltar, o que nas palavras de Kramer (1988), é uma ideia a ser reforçada. O fato do atendimento aos pequenos na Educação Infantil ser um direito destes, enquanto crianças, seres sociais, cidadãos, e não por serem filhos de mães e, mesmo, pais trabalhadores, que, claro, devem ter garantidos, assim, o dever de atendimento pelo Estado. A expansão da educação não pode, com isso, ficar atrelada ao mercado de trabalho feminino ou mesmo às necessidades econômicas do Estado, deve considerar, sim, a importância para a infância.

A concepção de criança que consta nestes e em tantos outros documentos, nos dá conta de uma noção construída ao longo da história e que vem mudando com o tempo, pois, esta não se apresenta nem na mesma sociedade de forma homogênea, são diversos os fatores (sociais, políticos, econômicos, étnicos), que irão contribuir para esta multiplicidade de infâncias. São singularidades que deverão ser respeitadas nesse processo educacional, afinal, 
[...] o direito à educação inclui também a exigência de qualidade e o respeito às necessidades da criança em cada fase do seu desenvolvimento: o direito à brincadeira, à atenção individual, ao aconchego e ao afeto, ao desenvolvimento da sociabilidade, assim como o direito à aprendizagem e ao conhecimento (CAMPOS, 2010, p.13-4)

E são estas crianças que, cada vez mais, de acordo com Didonet (2010), tem sua capacidade confirmada pela pedagogia e psicologia, pois, são protagonistas de iniciativas, descobertas, conhecimentos. De acordo com o autor (p. 24), "[...] desde que nasce a criança tem algumas capacidades e vai desenvolvendo novas a cada dia por força de uma competência própria e na interação com outras pessoas e com o meio físico.". Desconstroem-se, assim, antigos conceitos de que a infância é desprovida de capacidades, inferior frente aos adultos. Kramer (1988) considera a criança um ser político, já que é um cidadão inserido em uma sociedade, em uma classe social, possuidora de cultura e dentro de um determinado momento histórico, devendo ser entendida em sua continuidade. Desta maneira, é apto a construir e reconstruir hipóteses e conhecimentos.

Fonseca (2009), afirma, ainda, que o conhecimento é social, situado politicamente, sendo assim, não só sujeitos e saberes como espaço e tempo se produzem e reproduzem na história. Sendo sujeitos ativos,

[...] as crianças refletem e gradativamente tomam consciência do mundo de diferentes maneiras em cada etapa do seu desenvolvimento. As transformações que ocorrem em seu pensamento se dão simultaneamente ao desenvolvimento da linguagem e de suas capacidades de expressão. À medida que crescem, se deparam com fenômenos, fatos e objetos do mundo; perguntam, reúnem informações, organizam explicações e arriscam respostas; ocorrem mudanças fundamentais no seu modo de conceber a natureza e a cultura (BRASIL, 1998, v.3, p.169).

Seguindo esta linha de raciocínio, concordamos com Fonseca (2009), ao destacar o quão plural, diversa e complexa é a realidade do nosso Brasil, com destaque para as diferenças culturais, geográficas e econômicas. Logo, a aprendizagem e o ensino de História na Educação Infantil não podem ficar atrelados a algumas datas comemorativas, afinal, não podemos esquecer que a educação e a formação da consciência histórica não acontecem apenas nos bancos escolares, mas em diversos lugares e momentos, pois não podemos esquecer que,

[...] o meio no qual vivemos traz as marcas do presente e de tempos passados. Nele encontramos vestígios, monumentos, objetos, imagens de grande valor para a compreensão do imediato, do próximo e do distante. O local e o cotidiano como locais de memória são constitutivos, ricos de possibilidades educativas, formativas (FONSECA, 2009, p.116-7)

Nesta perspectiva, torna-se mais fácil situar o aluno, dentro de um determinado momento, e conduzi-lo a se reconhecer como ser histórico que vive e faz história desde a mais 
tenra idade e, assim, constrói sua identidade e estreita os laços de pertencimento com a cultura e o grupo social ao qual está inserido. Desta forma, Fonseca (2009, p.125), destaca que:

[...] o local e o cotidiano da criança e do jovem constituem e são constitutivos de importantes dimensões do viver - logo, podem ser problematizados, tematizados e explorados no dia a dia da sala de aula, com criatividade, a partir de diferentes situações, fontes e linguagens. Assim, o ensinar e o aprender História não é algo externo, a ser proposto e difundido com uma metodologia específica, mas sim algo a ser construído no diálogo, na experiência cotidiana, em um trabalho que valorize a diversidade e a complexidade de forma ativa e crítica.

Segundo o RCNEI (BRASIL, 1998, v. 3), é em processos de interação com outras crianças e estimulados pela mediação de conhecimentos provenientes de relatos orais, revistas, filmes, fotografias entre outros, e perpassadas por suas vivências que os pequenos poderão pensar e formular hipóteses sobre algo que querem conhecer. Corroborando com essa ideia, Fonseca (2009, p. 132-3) afirma que "A História tem o papel de auxiliar o aluno na busca de sentidos para as construções e reconstruções históricas. Espaço e tempo não são duas categorias abstratas, mas preenchidas de historicidade." Não é desperdício de tempo trabalhar o ensino de História nas classes de Educação Infantil, mais precisamente com alunos do préescolar, pois, como acabamos de ver, estes, tanto quanto os adultos, são produtores de cultura e protagonistas de seu conhecimento, todavia:

[...] as crianças devem, desde pequenas, ser instigadas a observar fenômenos, relatar acontecimentos, formular hipóteses, prever resultados para experimentos, conhecer diferentes contextos históricos e sociais, tentar localizá-los no espaço e no tempo. Podem também trocar ideias e informações, debatê-las, confrontá-las, distingui-las e representá-las, aprendendo, aos poucos, como se produz um conhecimento novo ou por que as ideias mudam ou permanecem (BRASIL, 1998, v. 3, p.172).

Acreditando nisso, podemos promover com crianças da pré-escola o ensinoaprendizagem de conhecimentos da disciplina de História que, geralmente, só são focados no Ensino Fundamental. Para que este trabalho seja desenvolvido de forma a conduzir as crianças a formularem suas próprias hipóteses acerca de um dado acontecimento, nada mais adequado do que utilizar como fonte histórica a imagem. Para Koehler (2012, p. 2-3), que acredita que a fotografia:

[...] inclui-se entre os novos documentos explorados pela historiografia, é amplamente disponível no mundo urbano, além de fazer parte do nosso sistema de representações e do imaginário social, constituindo cada vez mais a nossa memória, inclusive entre as camadas menos favorecidas da sociedade.

Sendo assim, enfatizamos neste projeto o uso da fotografia como um documento carregado de significados históricos, em que nas mãos das crianças vem a ser a história palpável e de fácil entendimento, Koehler (2012, p.3), ainda destaca o fato do uso de fontes imagéticas, "desenvolver a capacidade do aluno redigir e interpretar sobre a realidade 
local, reconhecendo e valorizando as memórias individuais e coletivas". Memórias fotográficas que registram os costumes e usos de uma sociedade, de uma época, independente da classe social a qual pertence, afinal para KOEHLER (2012, p. 4),

[...] com a popularização da máquina fotográfica, os arquivos pessoais compõem-se cada vez mais de imagens fotográficas, enfocando também aspectos da vida urbana, contendo signos próprios do seu grupo social ou comunidade. São reveladores de sua visão de mundo, costumes, valores e ideologias e da forma como percebem a cidade e dão significado ao mundo e às suas experiências imediatas.

Existem diferentes fontes que podem vir a acrescentar, compartilhar com as crianças seus conhecimentos. No caso das fotografias, mais claramente podemos observar as transformações vividas por um dado local ou grupo social. Koehler (2012) destaca que, ao usar de forma pedagógica a história local possibilitamos que nosso aluno desenvolva um pensamento histórico, facilitando a incorporação das memórias que compreendem o entorno do aluno, através de fontes orais, documentos escritos, fotografias. Assim, este se verá como sujeito histórico. Para a autora,

a partir do uso desses documentos, de uma problematização e da inserção de conteúdos que servem como embasamento teórico e para a leitura da relação entre passado e presente, produz-se o conhecimento histórico. As possibilidades de exploração de fontes são amplas e podem abranger os arquivos locais e os arquivos escolares. (KOEHLER, 2012, p. 7)

Como sujeito produtor de cultura, sim, porque independente da idade, podemos ver a participação das crianças no meio em que estão inseridas e como, a partir de algumas informações orais ou visuais, elas formulam hipóteses acerca da sua história, da história da humanidade.

\section{Perspectivas Teóricas: Início de uma Caminhada}

Com base em autores que se debruçam sobre a História da Educação Infantil, como Kuhlmann Jr. (2003), é possível dizer que, durante muito tempo, o cuidado e a educação das crianças menores de 06 anos ficou, exclusivamente, sob a responsabilidade das famílias. Apenas em meados do séc. XX, é que as primeiras instituições de Educação Infantil surgiram no Brasil, ligadas a organismos de assistência social e/ou saúde e não à educação, objetivando atender as crianças pobres, filhas de mães trabalhadoras. Ainda, segundo o mesmo autor, a qualidade na Educação Infantil, por muito tempo, esteve atrelada a uma tendência elitista, aos pobres apenas assistência, pois, eles não precisariam do mesmo tipo de educação das crianças da elite, servindo apenas para reproduzir desigualdades sociais.

Somente com a promulgação da Constituição Federal, em 1988, é que a Educação Infantil passou a fazer parte da área educacional, garantindo às crianças de zero a seis anos o 
atendimento em creches e pré-escolas sendo reconhecida como dever do Estado. No entanto, para Kuhlmann (2003, p.493), “[...] essa determinação constitucional ganha estatuto legal mais definido apenas oito anos depois, com a Lei de Diretrizes e Bases da Educação Nacional (LDB) 9.394/96.”. Em sua redação encontramos uma sessão específica acerca da Educação Infantil:

Art. 29. A educação infantil, primeira etapa da educação básica, tem como finalidade o desenvolvimento integral da criança de até 5 (cinco) anos, em seus aspectos físico, psicológico, intelectual e social, complementando a ação da família e da comunidade.

Art. 30. A educação infantil será oferecida em:

I - creches, ou entidades equivalentes, para crianças de até três anos de idade;

II - pré-escolas, para as crianças de 4 (quatro) a 5 (cinco) anos de idade.

Art. 31. A educação infantil será organizada de acordo com as seguintes regras comuns:

I - avaliação mediante acompanhamento e registro do desenvolvimento das crianças, sem o objetivo de promoção, mesmo para o acesso ao ensino fundamental;

II - carga horária mínima anual de 800 (oitocentas) horas, distribuída por um mínimo de 200 (duzentos) dias de trabalho educacional;

III - atendimento à criança de, no mínimo, 4 (quatro) horas diárias para o turno parcial e de 7 (sete) horas para a jornada integral;

IV - controle de frequência pela instituição de educação pré-escolar, exigida a frequência mínima de $60 \%$ (sessenta por cento) do total de horas;

$\mathrm{V}$ - expedição de documentação que permita atestar os processos de desenvolvimento e aprendizagem da criança. (BRASIL, 1996)

No ano de 1998, seguindo as determinações da LDB $n^{\circ}$. 9.394/96, foi apresentado pelo Ministério da Educação e do Desporto (MEC) o Referencial Curricular Nacional para a Educação Infantil (RCNEI), objetivando auxiliar os profissionais que atuam nesta área. Espera-se, assim, assinalar metas de qualidade que venham contribuir com o desenvolvimento integral das identidades infantis e com a realização da socialização em ambientes educacionais que proporcionem, não só o acesso, mas a ampliação de seus conhecimentos sociais e culturais.

Em 1999, o MEC instituiu as Diretrizes Curriculares Nacionais para a Educação Infantil (DCNEI). Estas tiveram uma nova publicação dez anos depois, em 2009. No entanto, para Kramer e Nunes (2007, p. 430), “[...] apesar da luta por mais atendimento à educação infantil, percebe-se a distância entre a realidade e a qualidade pretendida, a incoerência entre o discurso em defesa da educação infantil e a ausência de recursos e projetos efetivos.".

Como podemos observar, não há como separar a socialização do meio em que a criança vive e interage, pois, é nesta relação que acontece a construção do conhecimento e, consequentemente, a bagagem que a criança irá carregar durante sua vida. É na Educação Infantil que devemos começar a transportar estas vivências para a sala de aula, onde acontecerão as trocas com os colegas, provenientes de diferentes lugares. Nesta perspectiva, educar não pode ser um trabalho unilateral, não pode ser transmitido do professor para o 
aluno, como era disseminado pela educação tradicional e, ainda, seguido por muitos educadores, há de ser um ato dialógico, um processo de ensino-aprendizagem, de construção do conhecimento. Afinal, de acordo com o DCNEI (2010) a criança é um,

[...] sujeito histórico e de direitos que, nas interações, relações e práticas cotidianas que vivencia, constrói sua identidade pessoal e coletiva, brinca, imagina, fantasia, deseja, aprende, observa, experimenta, narra, questiona e constrói sentidos sobre a natureza e a sociedade, produzindo cultura (BRASIL, 2010, p. 12)

Todo trabalho desenvolvido com as crianças, no caso, pré-escolares, é compensador, pois, eles são transparentes, verdadeiros, se gostam do assunto, das atividades propostas participam através da linguagem oral, escrita, de gestos. Não precisam agradar ninguém para obter nota ou serem aprovados o que os torna autênticos, espontâneos na construção e reconstrução do próprio conhecimento. No entanto, estes conhecimentos são construídos, gradativamente, sempre permeados por atitudes que demonstrem curiosidade, hipóteses, refutação e reformulação de explicações.

Com o intuito de fomentar, entre as crianças, a construção de conhecimentos acerca do papel histórico e social da Escola Mal. Castelo Branco é que foram oferecidos materiais que despertassem seu interesse para este projeto, neste caso, fotografias que, ao serem manuseadas, conduziriam os alunos a conhecer contextos sociais diferentes dos seus, a se perceberem como agentes sociais de transformação, a trocarem ideias com os outros (colegas, professores, funcionários, familiares). Em outras palavras, a fotografia pôde levá-los a formular seus próprios conhecimentos com base nas imagens observadas e analisadas. Para Mauad (1996, p. 03):

[...] entre o sujeito que olha e a imagem que elabora há muito mais que os olhos podem ver. A fotografia - para além da sua gênese automática, ultrapassando a ideia de analogon da realidade - é uma elaboração do vivido, o resultado de um ato de investimento de sentido, ou ainda uma leitura do real realizada mediante o recurso a uma série de regras que envolvem, inclusive, o controle de um determinado saber de ordem técnica.

As mídias são importantes recursos pedagógicos, no caso da fotografia vem a ser uma fonte de múltiplas análises que são capazes de enriquecer a atividade docente e discente, ampliando o processo de ensino-aprendizagem. Não podemos considerar a fotografia, a imagem como meio direto de expressão do mundo, esta nada mais é que o olhar de alguém sobre algo e, provavelmente, cada olhar será diferente em sua análise. A criança segundo Rego (1995, p. 76),

[...] como membro de um grupo sócio-cultural determinado, vivencia um conjunto de experiências e opera sobre todo o material cultural (conceitos, valores, ideias, objetos concretos, concepção de mundo, etc.) a que tem acesso. Deste modo, muito antes de entrar na escola, já construiu uma série de conhecimentos do mundo que a cerca. 
O sujeito nasce e cresce como sujeito ativo, responsável, não só por criar, mas por recriar e, principalmente, interagir no meio e na realidade em que está inserido, portanto, não cabe a nós, professores, podá-los, muito pelo contrário, nosso papel é mediador. Nesta mesma ótica, Rego (1995, p. 108), destaca que a escola:

[...] não deve se restringir à transmissão de conteúdos, mas, principalmente, ensinar o aluno a pensar, ensinar formas de acesso e apropriação do conhecimento elaborado, de modo que ele possa praticá-las autonomamente ao longo de sua vida, além de sua permanência na escola.

Apesar de muitas vezes esquecermos, Vygotsky, em seus escritos, considera a importância das experiências trazidas da cultura em que a criança está inserida, afinal dentro de uma escola não há um tipo de aluno, estes são provenientes de diferentes tipos de famílias e de uma sociedade que está no entorno da escola. Esta escola, como destaca Rego (1995, p. 79), que "propicia às crianças um conhecimento sistemático sobre aspectos que não estão associados ao seu campo de visão ou vivência direta". Conhecimento este que foi construído e acumulado pela humanidade, e que todos os indivíduos, independente da classe social, tem direito ao acesso.

\section{A Caminhada: Trilhando Conhecimentos}

O projeto foi desenvolvido com alunos na faixa etária de 05 e 06 anos das duas turmas (manhã e tarde) de Pré-Escolares da Escola Municipal de Ensino Fundamental Marechal Castelo Branco, no município de Jaguarão/RS. Como uma atividade ou mesmo um projeto não pode surgir do nada começamos o trabalho com uma motivação, algo que chamou as crianças para a brincadeira e, consequentemente, para o diálogo. Desta forma, foi utilizado o "data show", em que foi colocado para os alunos um pequeno vídeo com a música "Bom dia, vou prá Escola", assim todos puderam cantar, questionar as imagens e descontraídos dar início às atividades;

Após este primeiro momento em que as crianças assistiram e interagiram com o vídeo, todos foram solicitados a sair de suas cadeiras e, juntamente com a professora, sentar em roda no chão. Neste momento, demos início à "Hora da Rodinha", espaço de conversa descontraída com as crianças, em que foi feita a delimitação do tema. Os alunos, aos poucos, foram sendo estimulados a falar sobre o que conheciam da escola, se algum familiar estuda ou estudou na instituição, a localização de suas casas em relação a esta, etc. Como é possível constatar,

\footnotetext{
${ }^{2}$ Música encontrada no link: http://www.youtube.com/watch?v=QhKs7Z9_iMo.
} 
A roda de conversa é o momento privilegiado de diálogo e intercâmbio de ideias. Por meio desse exercício cotidiano as crianças podem ampliar suas capacidades comunicativas, como a fluência para falar, perguntar, expor suas ideias, dúvidas e descobertas, ampliar seu vocabulário e aprender a valorizar o grupo como instância de troca e aprendizagem. A participação na roda permite que as crianças aprendam a olhar e a ouvir os amigos, trocando experiências (BRASIL, 1998, v. 3, p. 138)

Nesta interação, acabamos sabendo que alguns possuem irmãos mais velhos que estudam na Escola. A colega Ana Laura disse ter vindo para a escola onde o pai estudou quando pequeno, além de outros colegas que não tem irmãos, mas conhecem muitos vizinhos que estudam ou estudaram na Escola. Segundo o RCNEI, é na Educação Infantil que,

[...] a criança encontra possibilidade de ampliar as experiências que traz de casa e de outros lugares, de estabelecer novas formas de relação e de contato com uma grande diversidade de costumes, hábitos e expressões culturais, cruzar histórias individuais e coletivas, compor um repertório de conhecimentos comuns àquele grupo etc. (BRASIL, 1998, v. 3, p. 181)

Após este momento de diálogo, mediado pela professora, os alunos foram conduzidos até a biblioteca da Escola e, auxiliados pela professora responsável pela biblioteca, encontramos e começamos a manusear alguns álbuns de fotografias e quadros que mostram fatos e acontecimentos da história da Escola e de alunos e professores que ali passaram. É importante ressaltar que esta atividade envolveu alguns estranhamentos e, até mesmo, risadas pela forma como as crianças e adultos se vestiam, cortes de cabelo, exclamações de surpresa por reconhecerem pessoas e espaços de seu dia a dia. Como podemos constatar, é possível trabalhar o passado, a História de forma concreta, manuseando, comparando, descobrindo outras situações. Desta feita,

[...] o fato da organização dos lugares ser fruto da ação humana em interação com a natureza abre a possibilidade de ensinar às crianças que muitas são as formas de relação com o meio que os diversos grupos e sociedades possuem no presente ou possuíam no passado (BRASIL, 1998, v. 3, p. 184)

Assim, começou a análise de algumas fotografias que traziam, principalmente, imagens de como era a estrutura física da Escola, como em outras épocas, era a praça, as janelas, alguns móveis da biblioteca, etc. A partir desta análise, as crianças foram convidadas a "reviver" algumas destas imagens encontradas e perpetuadas nestas antigas fotografias. Em meio a muita euforia, foram feitas novas fotos, considerando alguns lugares e até mesmo pessoas que fizeram ou fazem parte da história desta instituição, como por exemplo a foto em que a Professora Paula Tatiana está na frente do prédio da escola com uma turma de alunos, e na qual foi convidada a reviver, outras professoras que ainda se encontravam atuando na mesma escola e que tinham sido reconhecidas em fotos antigas também reviveram junto aos alunos desta turma tais imagens. Os anos passam, as feições mudam mas, ainda é possível 
encontrar aspectos e pessoas que resistem ao tempo e continuam com suas atividades na mesma instituição.

Na figura 01, temos a praça da escola, local de uso dos alunos pré-escolares, quando teria sido instalada recentemente; na figura 02 , as crianças além de registrarem como a praça se encontra perceberam algumas diferenças como a presença da quadra de esportes aos fundos desta, construída anos depois, a fim de facilitar a prática de esportes pelos escolares, além do calçamento que substituiu a terra e a grama.

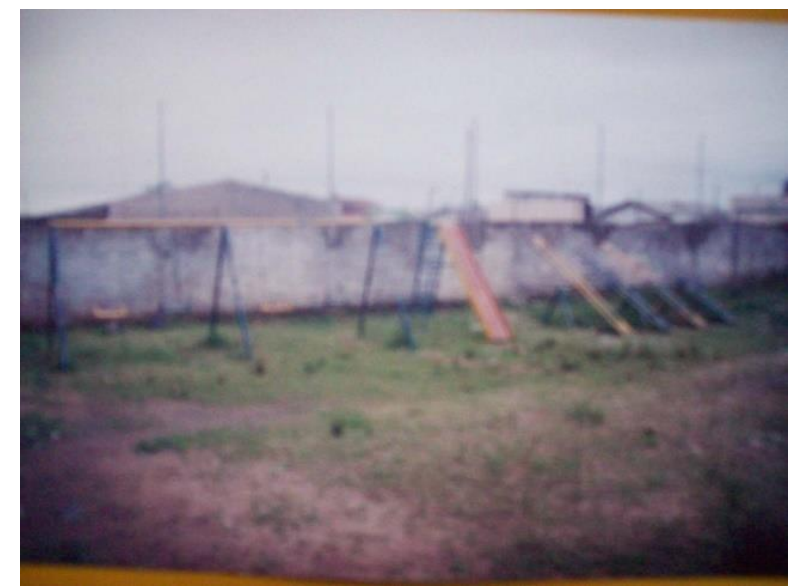

Fig. 01 - A praça da escola nos primórdios de sua instalação.

Fonte: A autora

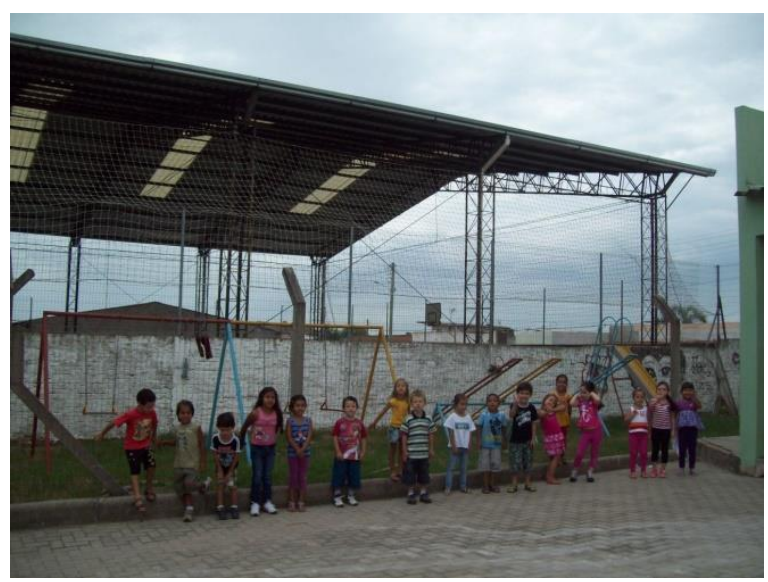

Fig. 02 - A praça atualmente, tendo ao fundo a quadra de esportes.

Fonte: A autora

No decorrer da atividade, continuamos a observar as fotos e procurando locais e pessoas que nos remetiam aos que convivíamos diariamente. Encontramos um quadro, fig. 03, que mostra como era a área interna do pátio da escola em sua fundação, no início da década de 1970. A fig. 04 mostra como ela está hoje. Assim, crianças perceberam o quanto a 
estrutura física da escola cresceu com o passar dos anos. Nesta análise, foi possível trabalhar alguns conceitos matemáticos como: tamanhos, quantidades, espaço, etc.

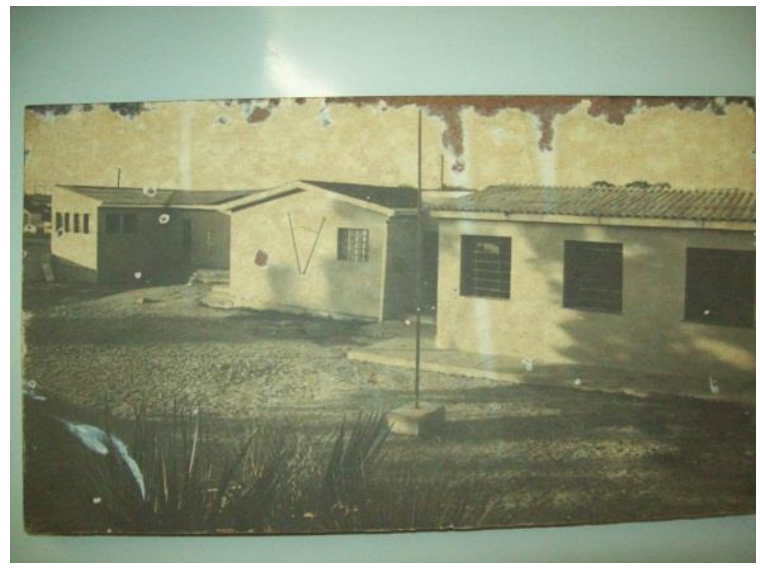

Fig. 03 - Área interna da Escola em sua fundação em meados dos anos 1970.

Fonte: A autora

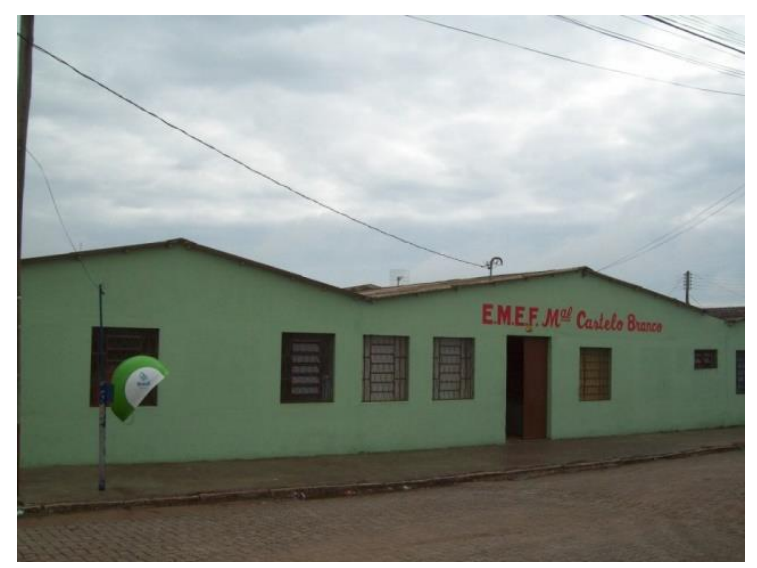

Fig. 04 - Área interna da Escola nos dias atuais, crescimento visível.

Fonte: A autora

Na sala de aula foi solicitado às crianças que fizessem um desenho, reproduzindo uma das fotografias observadas que mais lhes chamou a atenção, quer fosse de um lugar, uma pessoa ou o que lhes viesse à mente, sem pressões ou regras, apenas a livre expressão. Dentro da proposta feita aos alunos, destacamos que concordamos com o RCNEI (BRASIL, 1998, v. 3, p. 89), afinal, “o desenvolvimento da capacidade artística e criativa deve estar apoiado, também, na prática reflexiva das crianças ao aprender, que articula a ação, a percepção, a sensibilidade, a cognição e a imaginação.”. Na figura 05, Kauã, após algumas dúvidas acerca do que mais lhe chamou atenção, desenhou a Professora Paula Tatiana e os alunos, fazendo vários bonecos, pois, na foto tinha muita gente. Na figura 06, o Érik preferiu desenhar a quadra de esportes da Escola, afinal ele adora jogar futebol e basquete neste local. 


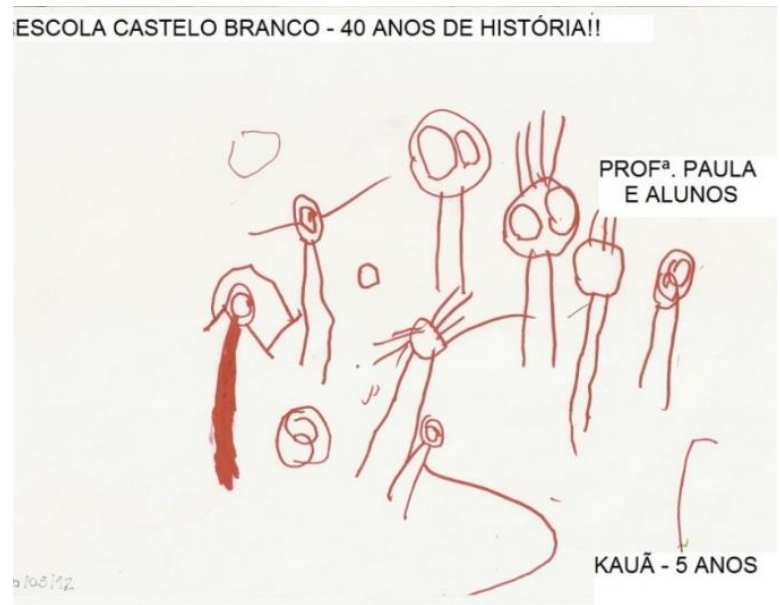

Fig. 05 - Representação da foto da Professora Paula Tatiana com os alunos.

Fonte: A autora

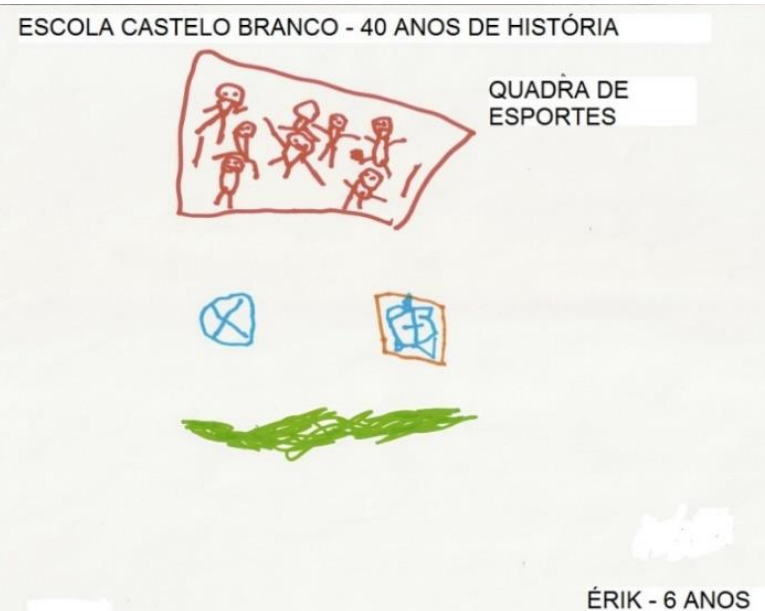

Fig. 06 - Representação da quadra de esportes da Escola.

Fonte: A autora

O Kainã preferiu usar uma das fotos como inspiração e, na fig. 07, podemos ver que ele desenhou a praça, especificamente, os balanços e, ao fundo, a quadra de esportes; não se esqueceu retratar parte do prédio da escola e suas janelas. Estes são alguns exemplos da expressão artística destes alunos do Pré-Escolar. 
RELACult - Revista Latino-Americana de Estudos em Cultura e Sociedade

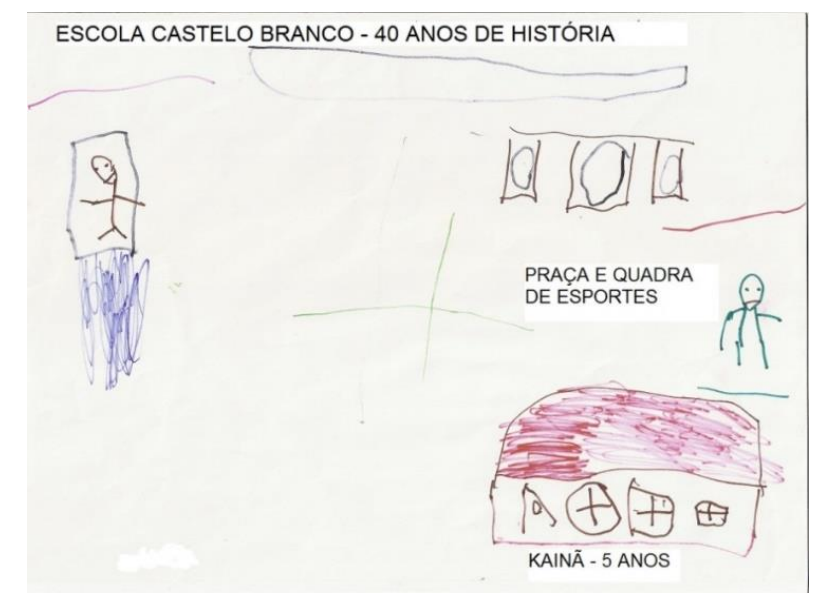

Fig. 07 - Representação da praça com a quadra de esportes ao fundo.

Fonte: A autora

Em outro momento, após a revelação das fotografias realizadas durante outros momentos mais intensos e mesmo divertidos, os alunos foram solicitados a formarem um círculo em volta de uma das mesas da sala, ao redor de materiais em que organizamos o "Mural: Ontem e Hoje", com as fotografias antigas analisadas e as atuais feitas pelo grupo. Esta atividade agitou as crianças, pois, estas acabaram reconhecendo os colegas e a si mesmos nas fotos, o que provocou comentários, como: "olha aqui, sou eu", "aonde estás colega, tu não veio?”, “eu tô bonita!", dentre outros. Desta forma, para Koehler (2012, p. 08):

O uso de imagens no ensino de história é uma necessidade constante do professor, que fala de um tempo e, senão também de um espaço, que não é o do aluno. A visualidade colabora com a percepção da representação sobre o tempo histórico.

Não podíamos deixar de expor este trabalho no hall de entrada da Escola, para que não só os pais vissem, mas, principalmente, os colegas das turmas do Ensino Fundamental, movimento registrado na figura 08 na hora do recreio, causando curiosidades entre os adolescentes.

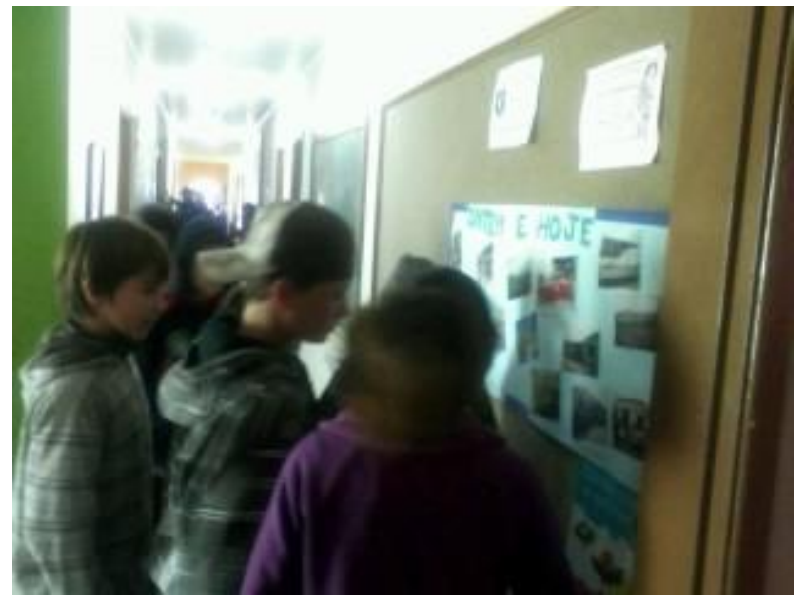

Fig. 08 - Alunos do Ensino Fundamental apreciando e analisando as fotos expostas. 


\section{Fonte: A autora}

A fim de registrar de forma lúdica esta atividade, elaboramos um pequeno vídeo sobre a Escola utilizando o programa "Movie Maker" e as fotografias usadas na atividade para, então, ser postado no blog "Pequenos Jaguarenses", este tem por objetivo aproximar o dia a dia das crianças em sala de aula de seus familiares. As crianças da turma do Pré-escolar adoram se "ver no computador", e solicitam que a professora faça o registro e a postagem no Blog para que os familiares possam vê-los. Com isso, ao chegar em casa, junto à mãe ou pai, contam o que fizeram durante a atividade e mostram as fotos, até mesmo, os pais que vivem em outras cidades também podem acompanhar o desenvolvimento de seus filhos.

Não podemos esquecer que é convivendo e interagindo, diariamente, com adultos e diferentes pares que a criança transforma sua realidade, produz e reproduz seus conhecimentos, em consequência a sociedade e a história. Para Rego (1995, p. 97), “[...] é entendido assim como um ser em permanente construção, que vai se constituindo no espaço social e no tempo histórico". A criança é, assim, protagonista da história em que está inserida.

\section{Breve Conclusão}

Ao longo deste processo de (re)contar a história por meio de fotografias, foi possível perceber e vivenciar etapas que permitiram a (re)construção da identidade social e imagética da Escola Marechal Castelo Branco. As fotografias utilizadas não só ilustraram, mas, principalmente, instigaram a participação das crianças, envolvidas, e de alguns adultos que, gentilmente, colaboraram para que as imagens fossem revividas, na (re)leitura deste espaço tão importante para esta comunidade. No entanto, para Koehler (2012, p. 08), o trabalho com fotografias vai mais além, pois,

[...] ao ler as fontes históricas imagéticas pode-se compreender as representações sociais de cada época, bem como desvendar o seu processo de produção e recepção. Dessa forma colabora-se para que o aluno tenha uma leitura mais crítica das imagens do seu cotidiano também.

Na vivência de atividades como esta, percebemos que não basta cumprir a legislação vigente para a Educação Infantil, é necessário que os profissionais invistam em atividades que permitam às crianças construir e reconstruir os conhecimentos adquiridos junto à família e ao grupo social. Através do diálogo, do manuseio de diferentes materiais é possível verificar que as crianças, mesmo pequenas em tamanho e em idade, formulam hipóteses, levantam premissas e projetam soluções em torno de temáticas sugeridas. Desta forma, começam a 
estabelecer as bases que os constituem enquanto cidadãos, produtores e reprodutores de cultura.

Assim sendo, a escola poderá de forma consciente desempenhar o seu papel, no que tange à formação para cidadania. Para isso, deve partir daquilo que a criança já sabe (o conhecimento que ela traz de seu cotidiano, suas ideias a respeito dos objetos, fatos e fenômenos, suas "teorias" acerca do que observa no mundo). A escola não pode desprezar que todo indivíduo se constitui não somente devido aos processos de maturação orgânica, mas, principalmente através de suas interações sociais. Construir conhecimentos implica numa ação partilhada com tudo e todos que estão a sua volta. É através dos outros que as relações entre sujeito e objeto de conhecimento são estabelecidas. Tal como Koehler (2012, p.09), ao propor este projeto, pretendia-se

[...] que o aluno percebesse que a fotografia não é uma simples imitação da realidade que serve para ilustrar o passado, mas que a compreendesse como um documento que é construído histórica e culturalmente. É uma representação da realidade que tem diferentes usos e significações no seu processo de construção, utilização, interpretação e apropriação,

Segundo a LDB 9.394/96, a avaliação na Educação Infantil será feita mediante acompanhamento e registro do seu desenvolvimento, sem o objetivo de promoção ou nota. Partindo desta premissa, acreditamos ter proporcionado aos alunos a construção de noções que envolvem espaço e tempo, inserindo-os na História da Escola, levando-os a conhecer alguns aspectos do passado e, ainda, se sentirem atores na construção do presente. Quanto ao uso de mídias imagéticas nesta faixa etária, vale ressaltar que estas foram muito bem recebidas, afinal causa motivação, euforia e curiosidade, impregnando o trabalho de significados e descobertas.

Percebemos que o uso de imagens (fotografias) conduziu as crianças do Pré-Escolar a estabelecer relações históricas de tempo e espaço entre seu grupo social e outros grupos. Estimulados pelo novo tema, perpassado por diálogo e por atividades com movimento, ou seja, que não se restringiram à sala de aula, sendo possível ver o quanto as crianças são capazes de criar hipóteses, resolver problemas e organizar seus conhecimentos junto a novas informações. Desta feita, esperamos ter deixado claro que fica impossível perpetuar conceitos distorcidos em que a Educação Infantil e os alunos menores de 06 anos não produzem História, não geram aprendizagens e que os professores apenas devem se responsabilizar pelo cuidado com seu corpo, sem fins educativos. 


\section{Referências}

BRASIL. Ministério da Educação. Lei de Diretrizes e Bases da Educação Nacional. LDB 9.394, de 20 de dezembro de 1996.

. Ministério da Educação e Cultura. Secretaria de Educação Fundamental. Referencial Curricular Nacional para a Educação Infantil. Brasília, 1998. v. 1, 2 e 3.

. Ministério da Educação. Secretaria de Educação Básica. Diretrizes Curriculares Nacionais para a Educação Infantil / Secretaria de Educação Básica. - Brasília: MEC, SEB, 2010.

CAMPOS, Maria Malta. A Educação Infantil como direito. In.: CAMPANHA NACIONAL PELO DIREITO À EDUCAÇÃO. Insumos para o debate 2 - Emenda Constitucional $\mathrm{n}^{\circ}$ 59/2009 e a educação infantil: impactos e perspectivas. São Paulo: Campanha Nacional pelo Direito à Educação, 2010.

DIDONET, Vital. Desafios legislativos na revisão da LDB: aspectos gerais e a Educação Infantil In.: CAMPANHA NACIONAL PELO DIREITO À EDUCAÇÃO. Insumos para o debate 2 - Emenda Constitucional n ${ }^{\circ}$ 59/2009 e a educação infantil: impactos e perspectivas. São Paulo: Campanha Nacional pelo Direito à Educação, 2010.

FONSECA, Selva Guimarães. Fazer e ensinar História. Belo Horizonte: Dimensão, 2009.

KRAMER, Sonia; NUNES, Maria Fernanda. Gestão pública, formação e identidade de profissionais de educação infantil. Cad. Pesquisa. São Paulo, v. 3, n. 131, ago. 2007. Disponível em <http://www.scielo.br/. Acesso em 20 mar. 2010.

KOEHLER, Ana Luiza. O ensino de História e a fotografia como representação: uma experiência através de fontes de arquivos locais. Disponível em: < http://www.diaadiaeducacao.pr.gov.br/portals/pde/arquivos/164-4.pdf> Acesso em: 28 mai 2012.

KUHLMANN JR. Moysés. Educando a infância brasileira. LOPES, E. M. T.; FARIA FILHO, L. M.; VEIGA, C. G. 500 anos de Educação no Brasil. 3. ed. Belo Horizonte: Autêntica, 2003

MAUAD, Ana Maria. Através da imagem: fotografia e história interfaces. Tempo, Rio de Janeiro, vol. $1, \quad \mathrm{n} \quad{ }^{\circ}$ 2, 1996, p. 73-98. Disponível em: http://www.historia.uff.br/tempo/artigos_dossie/artg2-4.pdf. Acesso em: 17 abr. 2012.

MORAN, José Manuel. As mídias na educação. 2008. Disponível em: http://eca.usp.br/prof/moran/midias_educ.htm. Acesso em: 16 abr. 2012.

REGO, Teresa Cristina. Vygotsky: uma perspectiva histórico-cultural da educação. Petrópolis, RJ: Vozes, 1995. 